\title{
Knowledge \& Practices Regarding Oral Cancer among Graduating Dental Students in Bhopal City, India
}

\author{
Aishwarya Singh ${ }^{1}$, Abhishek Harish ${ }^{2}$, Rajpreet Kaur ${ }^{3}$ \\ ${ }^{1}$ MDS, Associate Professor, Department of Dentistry, Government Medical College Hospital, Ambikapur, \\ Chhatisgarh, India. \\ ${ }^{2}$ MDS, Assistant Professor, Department of Dentistry, Government Medical College Hospital, Ambikapur, \\ Chhatisgarh, India. \\ ${ }^{3}$ BDS, Department of Dentistry, Government Medical College Hospital, Ambikapur, Chhatisgarh, India.
}

Corresponding Author: Aishwarya Singh

\begin{abstract}
Background: Evaluation of oral cancer related knowledge among dental students would aid in planning the oral health service programs and curriculum on large scale. The aim of this study was to assess the self reported knowledge and practice pattern of dental students in Bhopal, India.

Methods: The study population comprised of 200 dental students studying in final year and undergoing internship. Knowledge and practices were recorded using closed ended assessment form. Simple percentages were calculated to draw inferences.
\end{abstract}

Results: 68\% students agreed that their knowledge regarding the prevention and detection of oral cancer is current and adequate. A total of $178(89 \%)$ felt that there is need for additional training/information regarding oral cancer. Almost half 106 (53\%) agreed to have you ever attended any educational programs on oral cancers.

Conclusion: The knowledge of graduating dental students was found to be adequate. The need for regular clinical updation and practices related to screening cannot be ignored.

Keywords: dental students, knowledge, oral cancer, screening, tobacco

\section{INTRODUCTION}

According to World Health Organization, carcinoma of oral cavity in males in developing countries, is the sixth commonest cancer after lung, prostrate, colorectal, stomach and bladder cancer, while in females, it is the tenth commonest site of cancer after breast, colorectal, lung, stomach, uterus, cervix, ovary, bladder and liver. ${ }^{[1]}$

In spite of having a health warning on every packet of cigarettes, smoking in India is increasing rapidly, especially among the young people. A significant contributory factor to this increasing trend is aggressive marketing by tobacco companies and peer pressure. ${ }^{[2]}$ Therefore the prevention and control of smoking has become a global concern.

Moreover, in India, the extremely popular use of the smokeless tobacco product called gutkha, renders its population and especially its youth to a greater risk of developing oral submucous fibrosis, a premalignant disease resulting in increased incidence of oral cancer in younger patients. [3] It has been reported that lack of awareness among the general public about oral cancer its associated risk factors is the primary reason for delayed presentation. ${ }^{[4]}$

Early detection is the single most critical intervention influencing survival. The oral cavity is easily accessible and can be examined with little discomfort. Dentists, as primary care providers, can easily incorporate the screening protocol into their 
routine examinations. Nevertheless, some studies [5] have suggested that these professionals are not able to adequately detect oral cancer in its early stages due to their ineffective attitudes and lack of knowledge. Assessing the knowledge of dental students paves the way towards understanding their level of awareness in the early detection and prevention of oral cancer. This is further true for the graduating students i.e. final year students and interns.

Since there is no information regarding this issue among the dental students in Bhopal city, representing Central India the present study was conducted.

The aim of the present study was to assess the knowledge of dental students regarding oral cancer. The objectives were to identify deficiencies in knowledge of dental students, to formulate health education material for early detection of oral cancer, and to make suitable recommendations.

\section{MATERIALS \& METHODS}

Study setting: A cross sectional study was conducted on the dental students present in two randomly selected private dental colleges, in Bhopal city.

Study population: The study population consisted of 200 dental students who were studying in the clinical year in the college, i.e. students of fourth year and interns. Dental students who were uncooperative and did not gave consent, or refused to participate due to time and priority constrains were not included in the study. Participants were chosen for inclusion in the study using following criteria: who did not have any emergency constraints, and not having any difficulty in understanding the questionnaire given by the investigator.

\section{Study sampling and sampling technique:}

A non-probability convenient sampling was followed in the present study, where all the dental students present on the day of study were included. A total of 200 dental students, who were available at the time of study, participated.

Measurement \& instrument: The questionnaire recorded demographic details namely age, gender, and years of study. A pre-tested questionnaire [6] was used containing 10 questions. The structured, closed-ended questionnaires assessed knowledge of dental students regarding oral cancer.

Ethics \& informed consent: Before the start of survey, ethical clearance to conduct a study was obtained from the institute. Permission was taken from the administrators. It was assured that participants/college would not be individually identified in research reports, nor data from any single individual/single college will be conducted as report results. A written consent was signed by all the participants individually, which gave them detailed information about the study.

Data collection: Individual consent was taken prior to the start of survey. A schedule of the survey for data collection was prepared. On an average 25 students were interviewed per day. One of the investigators was present with the participants while the questionnaire was being filled to make sure that the participants were able to understand the questions and respond accordingly. The questionnaire took 3 minutes on an average to complete.

Statistical analysis: The data was transferred to pre-coded survey form to a computer. A master chart was created for the purpose of data analysis. Simple percentages were calculated using Statistical Package of Social Science (SPSS Version 20.0; Chicago Inc., USA).

\section{RESULTS}

A total of 200 dental students participated in the study, out of which 24 were male and 176 were female. The mean 
age of the study participants was $21.54 \pm 1.13$ years.

Table 1 depicts distribution of knowledge related response among the dental students. The self perceived responses were classified in three sections agree, don't know, and disagree. A total of $136(68 \%)$ students agreed that their knowledge regarding the prevention and detection of oral cancer is current and adequate and 138 (69\%) agreed that annual oral cancer examinations should be provided for those of 40-year of age and above. Majority of students 184 (92\%) agreed that patient's with suspected oral cancer lesions should be referred to a specialist. Early detection improves 5-year survival rates from oral cancer were agreed by $146(73 \%)$ students. A total of $178(89 \%)$ felt that there is need for additional training/information regarding oral cancer.

Table 1: Distribution of responses regarding knowledge

\begin{tabular}{|c|c|c|c|}
\hline \multirow[t]{2}{*}{ QUESTIONS } & \multicolumn{3}{|c|}{ RESPONSES } \\
\hline & Agree & Don't Know & Disagree \\
\hline My knowledge regarding the prevention and detection of oral cancer is current and adequate & $136(68 \%)$ & $56(28 \%)$ & $8(4 \%)$ \\
\hline Annual oral cancer examinations should be provided for those of 40 -year of age and above & $138(69 \%)$ & $28(14 \%)$ & $34(17 \%)$ \\
\hline Early detection improves 5-year survival rates from oral cancer & $146(73 \%)$ & $54(27 \%)$ & 0 \\
\hline Do you feel that there is need for additional training/information & $178(89 \%)$ & $16(8 \%)$ & $6(3 \%)$ \\
\hline
\end{tabular}

Table 2: Distribution of responses regarding practice

\begin{tabular}{|l|l|l|}
\hline QUESTIONS & RESPONSES \\
\cline { 2 - 3 } & Yes & No \\
\hline Do you examine the oral mucosa routinely? & $152(76 \%)$ & $48(24 \%)$ \\
\hline Do you take history from patient about alcohol and tobacco use? & $190(95 \%)$ & $10(5 \%)$ \\
\hline Do you refer the patients with suspicious lesions to a oral surgeon for further evaluation? & $178(89 \%)$ & $22(11 \%)$ \\
\hline Do you educate patients on the adverse effects of alcohol and tobacco and assist them in cessation & $194(97 \%)$ & $6(3 \%)$ \\
\hline Have you ever attended any educational programs on oral cancers? & $106(53 \%)$ & $94(47 \%)$ \\
\hline
\end{tabular}

Table 2 depicts distribution of practice related response among the dental students, which was recorded as either Yes or No. A total of $152(76 \%)$ responded that they examine the oral mucosa routinely. History from patient about alcohol and tobacco use was recorded by majority 190 $(95 \%)$ of students. The patients with suspicious lesions are referred to an oral surgeon for further evaluation by 178 (89\%) students. Majority of students $194 \quad$ (97\%) educate patients on the adverse effects of alcohol and tobacco and assist them in cessation. Almost half 106 (53\%) agreed to have you ever attended any educational programs on oral cancers.

\section{DISCUSSION}

Graduating dental should possess adequate level of awareness of oral health and its diseases so that this knowledge can be instilled among patients and community at large. Dentists, have the chance to diagnose oral cancer even in asymptomatic patients before dissemination occurs to adjacent tissues. Hence, it is the responsibility of the dental colleges to ensure the graduating dental students have solid technical, scientific, and ethical knowledge, aimed at promoting health, emphasizing the philosophy of prevention of prevalent oral diseases ${ }^{.[6]}$ It becomes the responsibility of dental colleges to instil basic knowledge on prevention and diagnosis of oral cancer. The methodological strength of the present study was that it was the first attempt of formal assessment of oral cancer knowledge, and practices among dental students of Bhopal City. It should also be taken into account that the questionnaire was not used for graduation purpose, hence the results represent the actual situation of knowledge and behaviour of graduating dental students. There were no controversies raised by the study.

In the present study, 24 were male and 176 were female, which is consistent with the fact that, in India, the profession of dentistry is largely practiced by females, as 
highlighted by a study conducted in Himachal. ${ }^{[6]}$ The mean age of the study participants was $21.54 \pm 1.13$ years.

The self perceived responses were classified in three sections agree, don't know, and disagree. A total of 136 (68\%) students agreed that their knowledge regarding the prevention and detection of oral cancer is current and adequate, which is in contrast to study done in Himachal [6] where $60.7 \%$ disagreed.

A total of $138(69 \%)$ agreed that annual oral cancer examinations should be provided for those of 40-year of age and above, similar to Himachal ${ }^{[6]}$ where 96.2 agreed. In contrast only $47 \%$ students from Karnataka ${ }^{[7]}$ believed that oral cancer most likely occurs in patients aged between 41 to 50 years.

Majority of students $184 \quad(92 \%)$ agreed that patient's with suspected oral cancer lesions should be referred to a specialist, similar to Himachal ${ }^{[6]} 99.1 \%$, Pune $^{[8]} 85 \%$, and Brazil ${ }^{[9]} 69.1 \%$ and in contrast with Chennai ${ }^{[10]}(36 \%)$. The study conducted in Chennai ${ }^{[10]}$ highlights that the dental students' knowledge though good is not adequate enough, and a more positive attitude must be emphasized when treating oral cancer patients.

In a study conducted in Yemen ${ }^{[11]}$ around $72.4 \%$ of students felt they did not have sufficient knowledge regarding prevention and early detection of oral cancer and $77.1 \%$ of Srilankan ${ }^{[12]}$ students agreed that early detection of oral cancer is difficult. In the present study Early detection improves 5-year survival rates from oral cancer were agreed by 146 (73\%) students, similar to Himachal ${ }^{[6]} 97.2 \%$.

A total of $178(89 \%)$ felt that there is need for additional training/information regarding oral cancer, similar to Himachal ${ }^{[6]} 99.1 \%$, Chennai ${ }^{[10]} 96 \%$, Dundee ${ }^{[13]}$ 90\% This highlights the knowledge gaps among dental students, and that there is a global need of educational intervention by implementing training or workshop particularly focusing on oral cancer.
Table 2 depicts distribution of practice related response among the dental students, which was recorded as either Yes or No. A total of $152(76 \%)$ responded that they examine the oral mucosa routinely, similar to study done in Karnataka ${ }^{[7]}(81 \%)$, although less as compared to study done in Malaysia $^{[14]}(100 \%)$. History from patient about alcohol and tobacco use was recorded by majority 190 (95\%) of students, similar to studies done in Karnataka ${ }^{[7]}(90 \%)$, Chennai ${ }^{[10]}(100 \%)$, and Nigeria ${ }^{[15]}$ $(96.7 \%)$. This is due to the fact the standard institutional case history recording by the students routinely involves recording of the personal addictive habits which majorly includes frequency of tobacco and alcohol usage.

The patients with suspicious lesions are referred to an oral surgeon for further evaluation by 178 (89\%) students, similar to study conducted in Malaysia ${ }^{[14]}(91.2 \%)$, .On the flip side studies conducted in Karnataka ${ }^{[7]}$ reveals only $38 \%$ students referred the cases to dentist. Whereas in a study conducted in Chennai ${ }^{[10]}, 36 \%$ students were not aware whom they should refer oral cancer patients.

It is a well known fact that oral cancer can be prevented by controlling risk factors such as use of tobacco and consumption of alcohol; hence it is necessary that the budding dentists educate their patients and emphasize on the importance of quitting these behaviours. It is observed that majority of students 194(97\%) in present study educate patients on the adverse effects of alcohol and tobacco and assist them in cessation, similar to study conducted in Yemen ${ }^{[11]}(95.7 \%)$, Himachal $^{[6]}(92.5 \%)$, and Brazil ${ }^{[9]}(82.1 \%)$.

Davis and colleagues in 2010 suggested that dental schools provide only "basic Knowledge -curricula that rarely incorporate effective, behaviorally- based components affecting long-term change ", and emphasized the importance of and need for new strategies regarding tobacco preventive activities. ${ }^{[16]}$ 
An alarming finding of the present study could be the small number of [106 $(53 \%)$ ] students agreeing to have ever attended any educational programs on oral cancers, which is although higher as compared to students from Himachal (4\%) ${ }^{[6]}$ still highlights the need of CDE programs related to oral cancer.

It can be concluded from the present study that the participants were aware of oral cancer, and had good self reported knowledge about the disease. Although one drawback of the study is that the practical knowledge is not checked in the current study. To further improve the knowledge dental students should be trained in giving health education with emphasis on oral cancer, on regular basis. Special sessions regarding screening, risk factors, clinical features and treatment options should be conducted exclusively for graduating dental students for additional training.

\section{Acknowledgement: None}

\section{Conflict of Interest: None}

\section{Source of Funding: None}

\section{Ethical Approval: Approved}

\section{REFERENCES}

1. Mehrotra R, Yadav S. Oral squamous cell carcinoma: Etiology, pathogenesis and prognostic value of genomic alterations. Indian Journal of Cancer 2006;43(2):60-6.

2. Alrsheedi M, Haleem A. Knowledge, attitude and behavior of medical and dental students towards smoking habit in Saudi Arabian universities a comparative study. International dental journal of student's research $2012 ; 1(1)$ : $1-16$.

3. Agrawal M, Pandey S, Jain S, Maitin S.Oral Cancer Awareness of the General Public in Gorakhpur City, India. Asian Pacific J Cancer Prev 2012;13(10):51959.
4. Shenoy N, Ahmed J, Saranya B, Shenoy A, Kamath P, Srikant N, Yadiya M. Oral Cancer Awareness among Undergraduate Medical Students of Dakshina Kannada, India. Sch J App Med Sci. 2013; 1(5):632- 6.

5. Nicotera G, Gnisci F, Bianco A, Angelillo IF. Dental hygienists and oral cancer prevention: Knowledge, attitudes and behaviors in Italy. Oral Oncol 2004;40:638-44.

6. Fotedar S, Bhardwaj V, Manchanda K, Fotedar V, Sarkar AD, Sood N. Knowledge, attitude and practices about oral cancers among dental students in H.P Government Dental College, Shimla-Himachal Pradesh. South Asian J Cancer 2015;4:65-7.

7. Gaddikeri K, Bhorgonde DD. Knowledge Assessment of Undergraduate Dental Students about Oral Cancer -An Institutional Study. Ann.Int. Med. Den. Res. 2017; 3(1):DE17-DE20.

8. Khatri JM, Goyal S, Parekh M, Jyothi PA, Hoshing C, Akifuddin S. Knowledge, attitude and awareness of oral carcinoma among dental practitioners - a survey. Int J Oral Care Res 2015;3(4):32-36.

9. Soares et al. Oral cancer knowledge and awareness among dental students. Braz J Oral Sci. 13(1):28-33.

10. Kumar and Harshini. Knowledge And Awareness About Oral Cancer Among Undergraduate Dental Students. Asian J Pharm Clin Res. 2016;9 (4):1-3.

11. Al-Maweri SA, Abbas A, Tarakji B, AlJamaei AS, Alaizari NA, Al-Shamiri HM. Knowledge and opinions regarding oral cancer among Yemeni dental students. Asian Pac J Cancer Prev. 2015;16:1765-70.

12. Jayasinghe RD, Sherminie LP, Amarasinghe H, Sitheeque MA.Level of awareness of oral cancer and oral potentially malignant disorders among medical and dental undergraduates. Ceylon Med J. 2016 ;61(2):77-9. 
13. Lachlan MC, Graham R, Ogden R. Oral cancer awareness of undergraduate medical and dental students BMC. Med Educ 2007;7:44.

14. Bhagavathula AS, Zakaria NB and Jamshed SQ. Knowledge of Future Dental Practitioners towards Oral Cancer: Exploratory Findings from a Public University in Malaysia. International Journal of Dentistry. 2015:1-6.

15. Okoh M, Enabulele J. Knowledge and practices regarding oral cancer among graduating dental students. Indian J Oral Sci 2015;6(1):14-8.
16. Davis JM, Ramseier CA, Mattheos N, et al (2010). Education of tobacco use prevention and cessation for dental professionals--a paradigm shift. Int Dent J, 60, 60-72.

How to cite this article: Singh A, Harish A, Kaur R. Knowledge \& practices regarding oral cancer among graduating dental students in Bhopal city, India. International Journal of Research and Review. 2021; 8(7): 353-358. DOI: https://doi.org/10. 52403/ijrr.20210749 